\title{
Role of Cytokines on the Progression of Liver
} Fibrosis in Mice Infected with Echinococcus multilocularis

\author{
Fengming Tian, ', $*$ Tao Jiang, ${ }^{2, *}$ \\ Xinwei Qi, ${ }^{3}$ Zhenyu Zhao, ${ }^{4}$ \\ Bin Li,' Madinaimu Aibibula,' \\ Hongyue Min, ${ }^{5}$ Jingyi Zhang, ' \\ Yumei Liu, ${ }^{3}$ Xiumin Ma (iD) ${ }^{1,3,5}$ \\ 'State Key Laboratory of Pathogenesis, \\ Prevention and Treatment of High \\ Incidence Diseases in Central Asia, Clinical \\ Laboratory Center, Tumor Hospital \\ Affiliated to Xinjiang Medical University, \\ Urumqi, Xinjiang, 8300 I I, People's \\ Republic of China; ${ }^{2}$ Animal Experiment \\ Center, First Affiliated Hospital of Xinjiang \\ Medical University, Urumqi, Xinjiang, \\ 8300 I I, People's Republic of China; ${ }^{3}$ State \\ Key Laboratory of Pathogenesis, \\ Prevention and Treatment of High \\ Incidence Diseases in Central Asia, First \\ Affiliated Hospital of Xinjiang Medical \\ University, Urumqi, Xinjiang, 8300II, \\ People's Republic of China; ${ }^{4}$ School of \\ Stomatology, Jilin University, Changchun, \\ Jilin, I3002I, People's Republic of China; \\ ${ }^{5}$ School of Basic Medicine, Xinjiang Medical \\ University, Urumqi, Xinjiang, 8300II, \\ People's Republic of China
}

*These authors contributed equally to this work

Correspondence: Xiumin Ma State Key Laboratory of Pathogenesis, Prevention and Treatment of High Incidence Diseases in Central Asia, Clinical Laboratory Center, Tumor Hospital Affiliated to Xinjiang Medical University, Urumqi, People's Republic of China

Email maxiumin1210@sohu.com

Yumei Liu

State Key Laboratory of Pathogenesis, Prevention and Treatment of High Incidence Diseases in Central Asia, First Affiliated Hospital of Xinjiang Medical University, Urumqi, Xinjiang, 8300 II, People's Republic of China Email 49644958@qq.com
Background: Liver fibrosis is a significant pathological change of Echinococcus multilocularis (E. multilocularis) infection. This study aimed to explore the role of cytokines on the progression of liver fibrosis in mice infected with E. multilocularis.

Methods: Liver histopathological features at 2, 8, 30, 90 and $180 \mathrm{~d}$ were quantified by inflammatory severity score. The expression levels of inflammatory cytokines, fibrosisrelated cytokines and hepatic cell apoptosis were measured using qRT-PCR and immunohistochemistry.

Results: At the early stage of infection, parasite stimulation triggers the rapid recruitment of immune cells, such as macrophages and neutrophils. These infiltrated immune cells then produce a large number of cytokines, such as iNOS (inducible nitric oxide synthase), a proinflammatory cytokine; TGF- $\beta$ (transforming growth factor) activated HSCs (hepatic stellate cells) to promote the proliferation of fibroblasts and secretion of ECM (extracellular matrix); MMP9 (matrix metalloproteinase 9) degraded basal ECM and facilitated its replacement by a highly dense interstitial matrix. At the middle and late stages of infection, the expression of IL-10 (interleukin-10) with general inhibitory effect was increased. The imbalance of fiber formation and degradation aggravated liver fibrosis. Meanwhile, the whole process of E. multilocularis infection was accompanied by the necrosis and apoptosis of hepatic cells. Conclusion: Along with the expansion of parasitic infection, dynamic changes in cytokine expression were observed on the liver fibrosis progression, which is helpful to provide some new ideas for the prevention and treatment of liver fibrosis in mice infected with E. multilocularis.

Keywords: Echinococcus multilocularis, liver fibrosis, infection immunity, cytokines, parasite

\section{Introduction}

Alveolar echinococcosis (AE) is one of the major public hazard diseases, characterized by continuous and infiltrative tumor-like growth of the Echinococcus multilocularis (E. multilocularis) metacestode stage over years or even decades in the organs of the intermediate host with estimated 17,400 infections per year. ${ }^{1,2}$ Studies showed E. multilocularis infections in China, mainly distributed in Xinjiang, Qinghai, Sichuan province and so on. ${ }^{3}$ E. multilocularis infection mainly affects the liver, and if the treatment is not timely, the fatality rate is often very high.

Liver fibrosis, as one of the histopathological phenomena in mice infected with E. multilocularis, is associated with aberrant apoptosis of hepatocytes, collagen 
formation and liver immune cells inflammation. ${ }^{4}$ In chronic and persistent inflammatory injuries, such as alcoholic hepatitis, viral hepatitis, parasitic diseases, and so on, this abnormal regulation of liver tissue repair mechanisms leads to irreversible fibrosis, more seriously, liver cirrhosis or liver cancer. Parasite stimulation triggers the rapid recruitment of immune cells, such as neutrophils and macrophages. These infiltrated immune cells then produce a large number of cytokines, such as iNOS (inducible Nitric Oxide Synthase) and IL-10 (interleukin-10); ${ }^{5}$ TGF$\beta$ (transforming growth factor) is a key mediator in immune response, matrix synthesis, cell proliferation, apoptosis, etc. ${ }^{6}$ more importantly, TGF- $\beta$ is also the main pro-fibrosis cytokine involved in the process of liver fibrosis. ${ }^{7}$ TGF- $\beta$ activates HSCs (hepatic stellate cells) to promote the proliferation of fibroblasts and secretion of ECM (extracellular matrix), which finally results in fibrosis occurrence. ${ }^{8}$ Liver microenvironment contains the interactions between HSC, liver resident immune cells, hepatocytes and/or sinusoidal endothelial cells, which are crucial for host defense and tissue remodeling. ${ }^{9}$ During liver pathophysiology, the interactions between HSCs and immune cells are critical to the deposition of ECM and the development of fibrosis, which are also mediated by cytokine signaling. ${ }^{10,11}$ Within hepatic damage, HSCs produce MMPs (matrix metalloproteinases) to degrade the basal ECM, facilitating its replacement by a highly dense interstitial matrix, while at the same time, promoting TGF- $\beta$ to release from pre-existing ECM, which is a reservoir of cytokines. $^{12}$ Therefore, it seems likely that the downregulation of MMPs may lead to a decrease in circulating TGF$\beta$ by inhibiting the secretion of the profibrogenic factor and blocking the deposition of high-density interstitial ECM, which may provide another possible antifibrotic mechanism. Caspases are a family of intracellular cysteine proteases that mediate apoptosis and inflammation through the processing and activation of pro-inflammatory cytokines, such as IL-1 $\beta$ (interleukin-1 $\beta$ ), IL-18, and IL-33. ${ }^{13}$ Studies have shown that hepatocyte apoptosis induces liver fibrosis, ${ }^{14}$ which is an excessive wound healing response to chronic liver injury, and hepatocytes death and collagen accumulation could reversely guide released chemokines by recruiting immune cells to further aggravate the inflammatory response. ${ }^{15,16}$

Although many CCL4-induced models have allowed us to gain a deeper understanding of the complexity of liver inflammation and repair, the composition of the ECM in E. multilocularis infection is less well studied. In our study, a mice model of E. multilocularis infection was successfully established, dynamic changes of cytokine expression were observed on the liver fibrosis progression, which is helpful to provide some ideas for the prevention and treatment of liver fibrosis in mice infected with E. multilocularis.

\section{Materials and Methods}

Animals and Infected-Model

\section{Establishment}

BALB/c mice (female, 8-week-old) purchased from the Experimental Animal Science Research Department (Urumqi, China) were maintained in an air-conditioned animal room with a 12-h light/dark cycle and provided with rodent chow and water. E. multilocularis protocercaria were obtained from intraperitoneal lesions maintained in BALB/c. All animals were treated according to the guidelines of the Institutional Animal Care, with protocols approved by the Institutional Animal Use and Care Committee of Xinjiang Medical University (No. 20170214-106). All animals received humane care according to the criteria outlined in the Guide for the Care and Use of Laboratory Animals prepared by the National Academy of Sciences and published by the National Institutes of Health (NIH publication 86-23, revised 1985). Specifically, mice were intraperitoneally (left lower quadrant) injected with $5 \%$ chloral hydrate $0.15-0.20 \mathrm{~mL} /$ mouse through medical syringe needle, and peripheral blood was collected by retro-orbital bleeding after successfully anesthetized; then, whole liver samples were obtained surgically; at last, mice were euthanized using cervical dislocation; the dead body further packed with special medical waste bags to freeze under $-20^{\circ} \mathrm{C}$ and delivered for biosafety handling. A $50 \mathrm{~mL}$ syringe was used to aseptically remove the swelling solution, and the remaining tissue was removed and placed into a sterile mortar for grinding. The grinded tissue was diluted by the prepared saline $(0.9 \%$ saline mixed with $500 \mathrm{U} / \mathrm{mL}$ penicillin and $100 \mathrm{U} / \mathrm{mL}$ streptomycin) and screened by a 200-mesh nylon. The filtrate was collected in a $50 \mathrm{~mL}$ centrifuge tube and left to settle in the protocercaria. After most of the protocercaria was precipitated, the supernatant was discarded, and then rinsed with the prepared saline until it was clear. The final precipitation was reconstituted with $\mathrm{PBS}$ and the protocercaria counted (DMI 4000B microscope, Leica, Germany) and adjusted to the appropriate parasite concentration before injection. The parasite vitality was determined by eosin 
exclusion. Only parasite batches exhibiting over $95 \%$ vitality were used. ${ }^{17}$ After suspension, it was prepared into a protocercaria suspension of 2000 protocercaria $/ \mathrm{mL}$ for later use. Mice were anesthetized by $2.5 \%$ chloral Hydrate, each mouse was intraperitoneally injected with $1 \mathrm{~mL}$ of protocercaria suspension (in the control group, mice injected with the same amount of normal saline).

\section{Serum and Liver Tissue Samples}

Mice peripheral blood was collected by retro-orbital bleeding after being successfully anesthetized at the time points $(2,8,30,90$ and $180 \mathrm{~d})$. Some liver tissue was fixed in $10 \%$ formalin for $24 \mathrm{~h}$ and embedded in paraffin, while others were quickly frozen in liquid nitrogen and stored at $-80^{\circ} \mathrm{C}$.

\section{Measuring ALT and AST Expression in Serum}

Mice peripheral blood was collected by retro-orbital bleeding after being successfully anesthetized (anticoagulant, Edathamil dipotassium salt, EDTA-K2). Liver injury was estimated by the increased activity of serum alanine aminotransferase (ALT) and aspartate aminotransferase (AST), which were evaluated by an automatic biochemistry analyzer (Hitachi, Ltd, Kokubunji, Tokyo, Japan).

\section{Liver Histopathological Evaluation}

The liver tissues were fixed in 4\% paraformaldehyde solution, embedded in paraffin for histological examinations and stained with haematoxylin-eosin (H\&E) and Masson's trichrome, assessing liver pathological changes and fibrosis degrees. For H\&E staining, the sections were dehydrated into water, stained with hematoxylin (Baoman Biotechnology, Shanghai, China) for $10 \mathrm{~min}$ and rapidly washed with running water around $30 \mathrm{~s}$. Then, the sections were differentiated by $1 \%$ hydrochloric acid and alcohol, washed by running water again around $1 \mathrm{~min}$, stained with eosin at room temperature around 5 min, dehydrated by graded ethanol and cleared by xylene once around $1 \mathrm{~min}$. The sections were sealed with neutral gum, and the pathological changes were observed and photographed under a microscope. Two experienced pathologists blindly gave a score of severity in mice infected with E. multilocularis (Table 1).

For Masson staining, sections were dewaxed into water, stained with hematoxylin for 10 minutes, rinsed with water, followed by hydrochloric acid for several seconds, rinsed with water again, and stained with ammonia for several minutes. Then, garnet magenta, 12-molybdenum-phosphate solution and green staining solution were successively dyed for about $10 \mathrm{~s}$, about $3 \mathrm{~min}$, about $4 \mathrm{~min}$. The slices were washed with water and air-dried, sealed with neutral adhesive, observed and photographed under a microscope. $\times 200$ Histopathological changes were observed under a microscope. Image $J$ was used to analyze 5 discontinuous random organization fields and obtain the mean value.

\section{Immunohistochemistry (IHC) for Detection of Cytokines Secretion in Liver Tissue}

Liver tissue sections $(3 \mu \mathrm{m})$ were hydrated and inactivated with $3 \% \mathrm{H} 2 \mathrm{O} 2$. Incubate with goat serum at room temperature for $30 \mathrm{~min}$. iNOS antibody (Abcam, Cambridge, UK, ab115819, dilution 1:200), IL-10 antibody (Bioss, Beijing, China, bs-0698R, 1:200), TGF- $\beta$ antibody (Affinity, Cincinnati, US, AF5347, dilution 1:200), $\alpha$ SMA antibody (Affinity, Cincinnati, US, AF1032, dilution 1:200), COL1 $\alpha 1$ antibody (Affinity, Cincinnati, US, AF7001, dilution 1:200), MMP9 antibody (Affinity, Cincinnati, US, AF5228, dilution 1:200) or Caspase 3 antibody (Affinity, Cincinnati, US, AF6311, dilution 1:200) were incubated overnight at $4^{\circ} \mathrm{C}$. The tablets were washed the next day, and the second antibody labeled with horseradish peroxidase was incubated at $37^{\circ} \mathrm{C}$ for $60 \mathrm{~min}$. Sections were developed with DIAMinobenzidine (DAB) and stained with hematoxylin. The slides were rinsed with distilled water and air-dried, sealed and placed under a microscope for observation. Image J software was used to evaluate the mean optical density of immunohistochemical images.

\section{Quantitative Real-Time PCR for Detecting mRNA Expression}

Total RNA was isolated from liver tissue employing a Trizol $^{\mathrm{TM}}$ isolation kit (Takara Bio, Dalian, China) as per manufacturer's instructions, subsequently converted to cDNA, which was carried out using PrimeScript reagent kit with gDNA Eraser (Takara Bio, Dalian, China), and subjected to real-time PCR using SYBR Premix Ex TaqII (Takara Bio). The primers for GAPDH, iNOS, IL-10, TGF- $\beta, \alpha$-SMA, col1 $\alpha 1$, MMP9 and caspase 3 were synthesized by Sangon Biotech (Shanghai, China), details showed in Table 2. Real-Time PCR was operated on ABI Prism 7500 Sequence Detection System (BioRad, Life 
Table I Hepatic Infection of Echinococcus multilocularis Severity Score (Mouse)

\begin{tabular}{|c|c|c|c|c|}
\hline \multicolumn{2}{|l|}{ Degree of Inflammation } & \multirow{2}{*}{$\begin{array}{l}\text { Vesicles* } \\
\text { (Number) }\end{array}$} & \multirow{2}{*}{$\begin{array}{l}\text { Abnormal Structures } \\
\text { and Substances }\end{array}$} & \multirow[t]{2}{*}{ Score } \\
\hline Hepatic Lobule & Portal Area and Surrounding & & & \\
\hline No inflammation & No inflammation & 0 & No obvious change & 0 \\
\hline $\begin{array}{l}\text { Degeneration, small amount spotted } \\
\text { and focal necrosis }\end{array}$ & $\begin{array}{l}\text { Mild inflammation (Inflammatory cells occupy } \\
\text { less than } 1 / 3 \text { of the portal area) }\end{array}$ & $\mathrm{I}-3$ & Granuloma & I \\
\hline $\begin{array}{l}\text { Degeneration, large amount spotted } \\
\text { and focal necrosis }\end{array}$ & & $4-6$ & & 2 \\
\hline Confluent necrosis or bridging necrosis & $\begin{array}{l}\text { Moderate inflammation (Inflammatory cells } \\
\text { occupy } 1 / 3 \sim 2 / 3 \text { of the portal area) }\end{array}$ & $7-9$ & $\begin{array}{l}\text { Laminated layer and } \\
\text { germinal layer }\end{array}$ & 3 \\
\hline $\begin{array}{l}\text { Extensive bridging of necrosis and } \\
\text { involved many hepatic lobules }\end{array}$ & $\begin{array}{l}\text { Severe inflammation (Inflammatory cells occupy } \\
\text { more than } 2 / 3 \text { of the portal area) }\end{array}$ & $\geq 10$ & $\begin{array}{l}\text { Brood capsule and } \\
\text { protoscolex }\end{array}$ & 4 \\
\hline
\end{tabular}

Note: *The average number of vesicle counts was observed in at least 3 different fields under low power microscope (magnification, $\times 100)$.

Science Research, Hercules, CA, USA). PCR conditions were as follows: one cycle at $95^{\circ} \mathrm{C}$ for $30 \mathrm{~s}, 40$ cycles at $95^{\circ} \mathrm{C}$ for $5 \mathrm{~s}$, at $61^{\circ} \mathrm{C}$ for $30 \mathrm{~min}$. All samples were run in triplicates. Relative mRNA abundances were determined with $2^{-\Delta \Delta \mathrm{Ct}}$ method using GAPDH gene to normalize.

\section{Statistical Analysis}

The quantitative analysis of morphology results was carried out using Image J. Data were analyzed by SPSS 21.0 (IBM, Chicago, IL, USA) or GraphPad Prism 8.0 software (GraphPad Software, San Diego, CA, USA). Results were expressed as means \pm standard error of mean (SEM). Differences between groups were analyzed, according to variable distribution using $t$-test/Mann-Whitney for two groups or ANOVA/Kruskal-Wallis (with Bonferroni or Dunn posttests, respectively) for three or more groups. A P-value $<0.05$ was considered to be statistically significant.

\section{Results}

Severity of Inflammation and Fibrosis Was Aggravated in Mice Infected with

\section{E. multilocularis}

Liver specimens stained by H\&E from the control group showed normal features with hepatocytes, liver architecture, central veins and portal areas. The mice infected with E. multilocularis resulted in distortions of the normal hepatic architecture with swollen hepatocytes around the central veins and interruption of hepatic tissue by numerous fibrous septa together with diffuse cellular infiltration around the fibrous bands and dilated portal areas. Furthermore, the vesicle structure could be observed in $90 \mathrm{~d}$ and $180 \mathrm{~d}$ infection (Figure 1). Based on the characteristics of E. multilocularis infection in mice, we invited two experienced pathologists to develop inflammatory infection scores (Table 1). After summing up the scores, the higher the score, the more severe the infection (Figure 2A). Masson staining results analyzed by image $\mathrm{J}$ showed that in the model group, the area of collagenous fibrosis in the liver tissues significantly increased (Figures 1 and 2B).

\section{Liver Function of Mice Infected with E. multilocularis at Different Stages}

The increased ALT and AST indicated the damage to hepatocytes. In the model group of mice infected with

Table 2 Primer Sequence

\begin{tabular}{|c|c|}
\hline Gene (Mouse) & Primer $\left(5^{\prime} \rightarrow 3^{\prime}\right)$ \\
\hline iNOS & $\begin{array}{l}\text { Forward:GCAGAGATTGGAGGCCTTGTG } \\
\text { Reverse:GGGTTGTTGCTGAACTTCCAGTC }\end{array}$ \\
\hline IL-I0 & $\begin{array}{l}\text { Forward:ATAAGAGCAAGGCAGTGGAGC } \\
\text { Reverse:GGCCTTGTAGACACCTTGGTC }\end{array}$ \\
\hline TGF- $\beta$ & $\begin{array}{l}\text { Forward:AGCTGCGCTTGCAGAGATTA } \\
\text { Reverse:GACAGCCACTCAGGCGTATC }\end{array}$ \\
\hline$\alpha-S M A$ & $\begin{array}{l}\text { Forward:GTCCCAGACATCAGGGAGTAA } \\
\text { Reverse:TCGGATACTTCAGCGTCAGGA }\end{array}$ \\
\hline Coll $\alpha \mid$ & $\begin{array}{l}\text { Forward:TAAGGGTCCCCAATGGTGAGA } \\
\text { Reverse:GGGTCCCTCGACTCCTACAT }\end{array}$ \\
\hline MMP9 & $\begin{array}{l}\text { Forward:GGACCCGAAGCGGACATTG } \\
\text { Reverse:CGTCGTCGAAATGGGCATCT }\end{array}$ \\
\hline caspase 3 & $\begin{array}{l}\text { Forward:CTCGCTCTGGTACGGATGTG } \\
\text { Reverse:TCCCATAAATGACCCCTTCATCA }\end{array}$ \\
\hline GAPDH & $\begin{array}{l}\text { Forward:TGGTGAAGCAGGCATCTGAG } \\
\text { Reverse:TGAAGTCGCAGGAGACAACC }\end{array}$ \\
\hline
\end{tabular}

Abbreviations: iNOS, inducible nitric oxide synthase; IL-I0, interleukin-10; TGF$\beta$, transforming growth factor- $\beta$; $\alpha$-SMA, $\alpha$-smooth muscle actin; Coll $\alpha$ l, collagen type I alpha I; MMP9, matrix metalloproteinase 9; GAPDH, glyceraldehyde-3-phosphate dehydrogenase. 


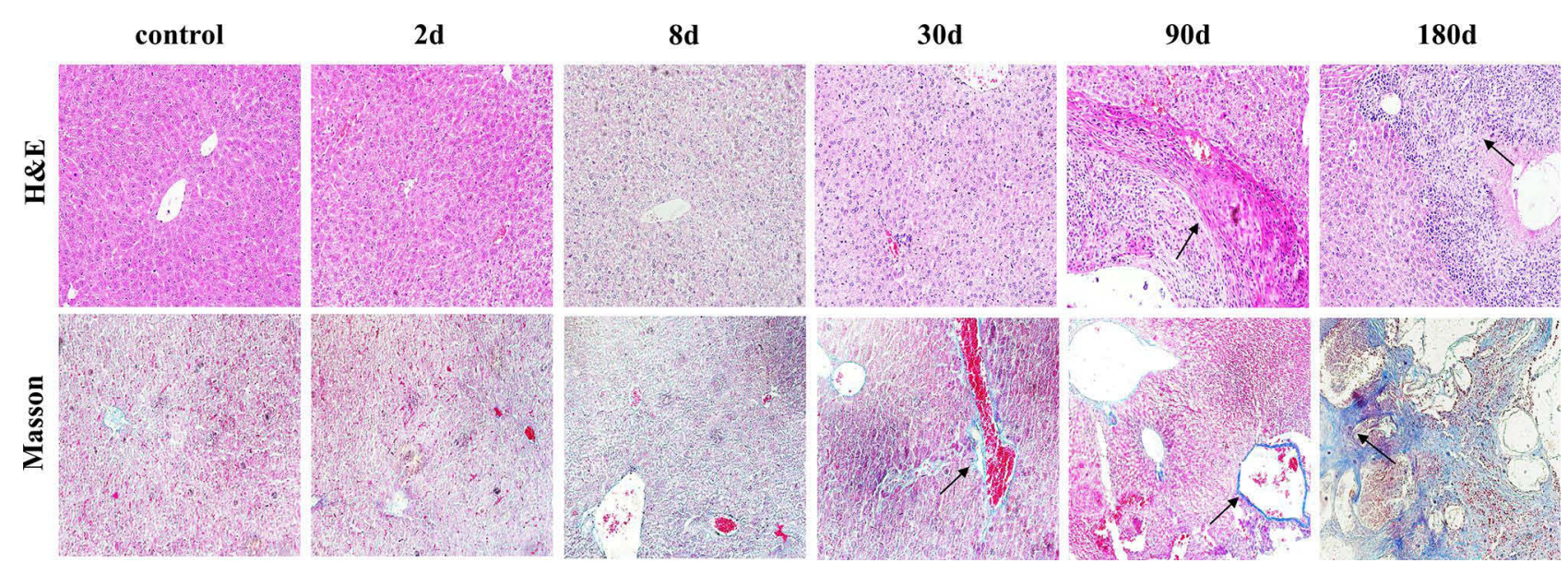

Figure I Pathological changes in the liver of mice infected with Echinococcus multilocularis $(\times 200)$.

Note: Immune cell infiltration and fibrosis change are showed with arrows.
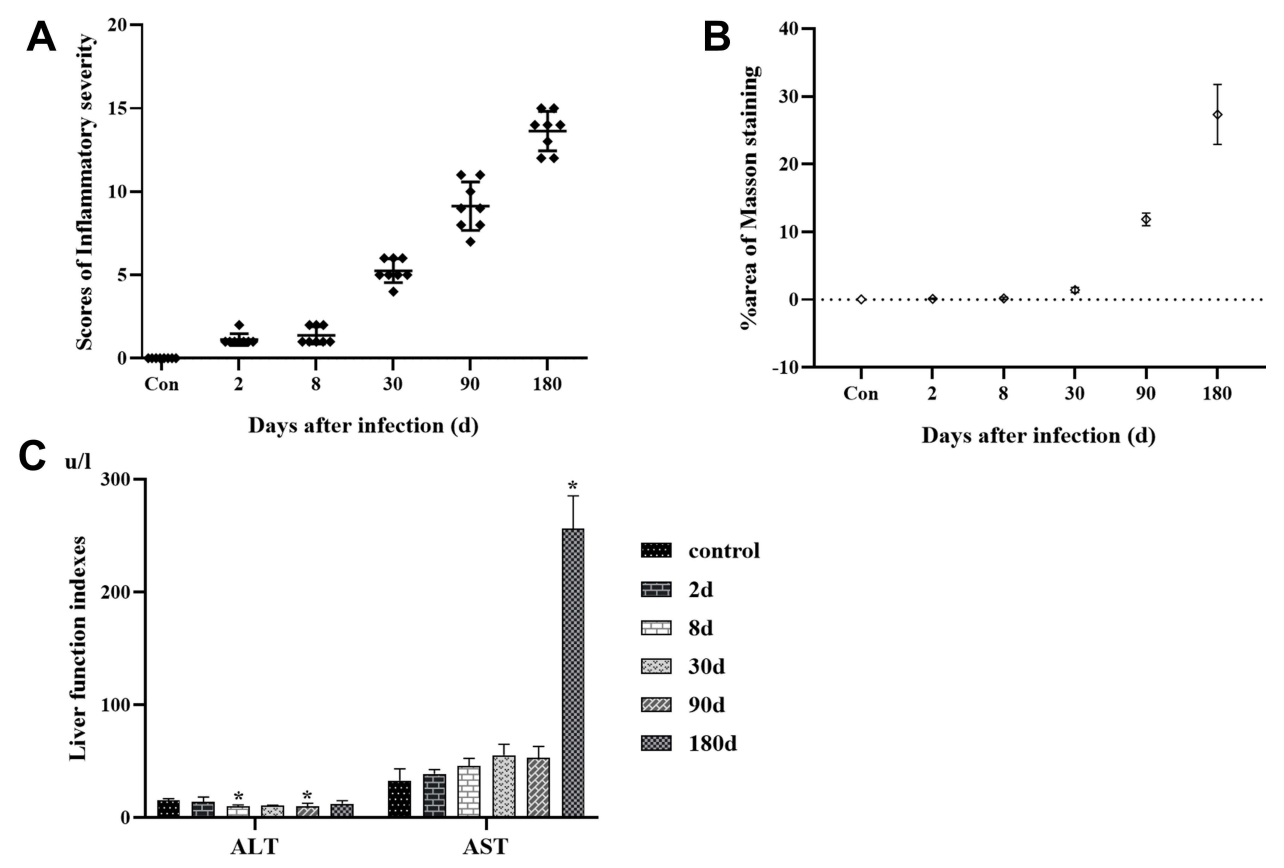

Figure 2 (A) Liver inflammatory severity scores Note, $n=8$ in each group, $\$$ Indicates the score of inflammatory severity in each mouse; (B) dynamic quantification of fibrosis area Note, Olndicates the average area percent in Masson staining of different group; (C) liver function in mice infected with Echinococcus multilocularis.

Note: *Compared with the control group, $\mathrm{P}<0.05$.

Abbreviations: ALT, alanine aminotransferase; AST, aspartate aminotransferase.

E. multilocularis, serum ALT increased at a low level in each period of infection, and the increase was not obvious, and even decreased at $8 \mathrm{~d}$ and $90 \mathrm{~d}$ points after infection compared with the control group $(\mathrm{P}<0.05)$. The reason might be related to the disorder of the liver immune microenvironment and hepatocytes necrosis (Figure 2C). When hepatocytes necrosis is severe, AST in mitochondria is released. A high AST can reflect the severity of liver cell injury and more importantly the severity of liver cell injury.
Compared with the control group, it showed a rapid increase at $180 \mathrm{~d}$ after infection $(\mathrm{P}<0.05)$ (Figure $2 \mathrm{C}$ ).

\section{Dynamic Changes of Inflammatory Cytokines in the Liver of Mice Infected with E. multilocularis}

iNOS, as one pro-inflammatory cytokine, responds positively when stimulated by parasites and expressed in almost all hepatocytes, mainly in hepatocyte plasma and 
infiltrated inflammatory cells. As shown in Figures 3 and $4 \mathrm{~A}$, at the $8 \mathrm{~d}$ infection, the expression of iNOS was strongly positive $(\mathrm{P}<0.05$, compared with the control or
$2 \mathrm{~d}$ model group), which suggested that inflammatory cells quickly recruited a large number of inflammatory cells to the injured liver tissue at the early stage of parasitic

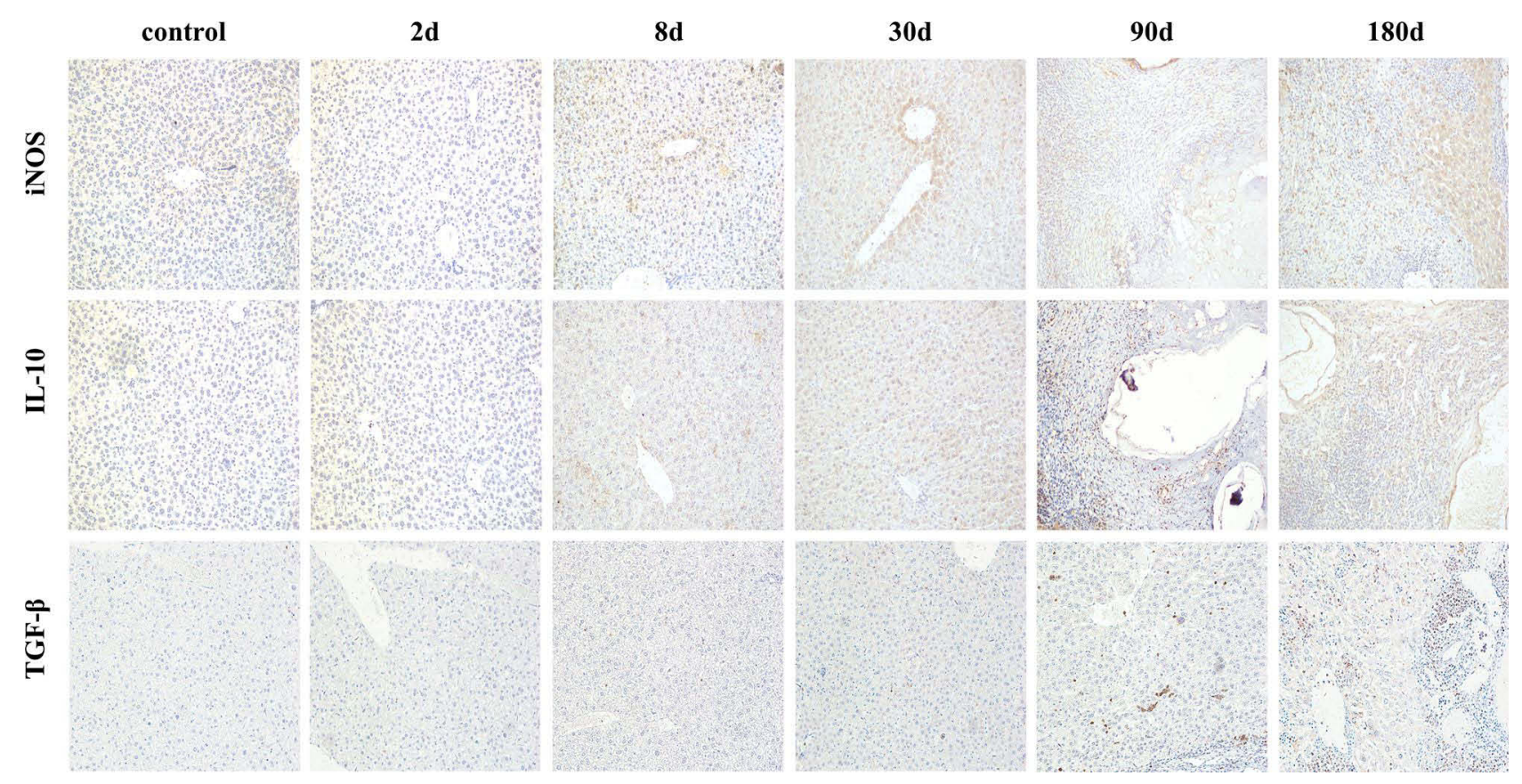

Figure 3 Dynamic changes of inflammatory cytokines in immunohistochemistry $(x 200)$.

Abbreviations: iNOS, inducible nitric oxide synthase; IL-10, interleukin-10; TGF- $\beta$, transforming growth factor- $\beta$.
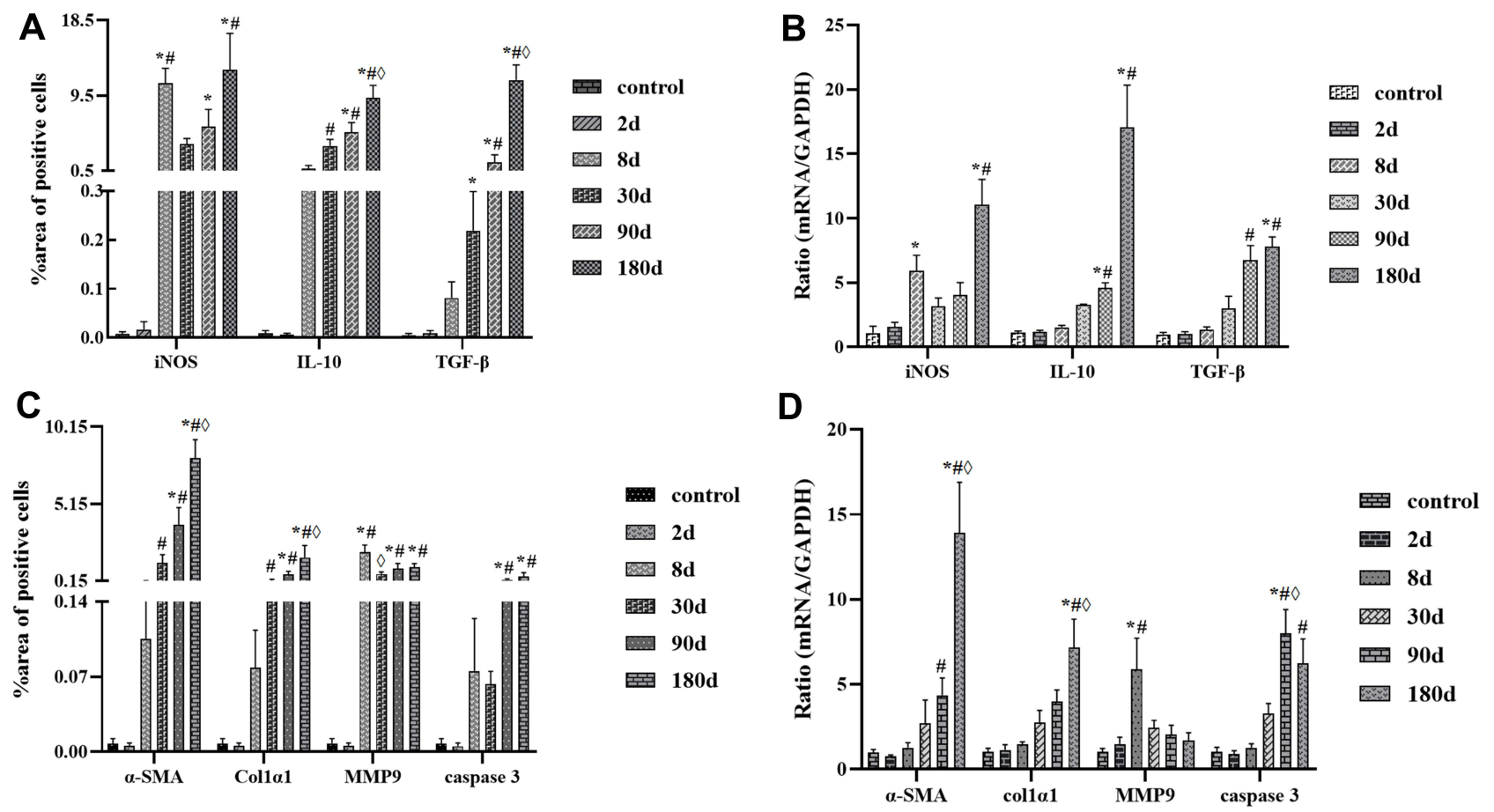

Figure 4 (A and C) Dynamic quantification of cytokines' expression in protein level; (B and D) Dynamic quantification of cytokines' expression in mRNA level. Notes: *Compared with the control group, $\mathrm{P}<0.05$; " Compared with the infection model of $2 \mathrm{~d}$ group; $\searrow$ Compared with the infection model of $8 \mathrm{~d}$ group.

Abbreviations: iNOS, inducible nitric oxide synthase; IL-I0, interleukin-I0; TGF- $\beta$, transforming growth factor- $\beta$; $\alpha$-SMA, $\alpha$-smooth muscle actin; Coll $\alpha$ I, collagen type I alpha I; MMP9, matrix metalloproteinase 9. 
invasion to promote the immune response. IL-10 can underregulate the pro-inflammatory response and liver fibrosis, ${ }^{18}$ it showed a weak positive expression at the early stage of infection but a strong positive expression mainly at the middle and late stages of infection. TGF- $\beta$, as an important mediator of inflammatory response and tissue repair, was strongly positive mainly at the middle and late stages of infection (Figures 3 and 4A). At the gene expression level, the results were essentially similar to those at the protein level (Figure 4B). With continuous stimulation of parasite, the lesion continues to expand, and the liver microenvironment is further disturbed for a long time. Mainly at the middle and late stages of infection, iNOS, IL-10 and TGF- $\beta$ all showed high expression levels ( $\mathrm{P}<0.05$, compared with the control group), especially at $30 \mathrm{~d}, 90 \mathrm{~d}$ and $180 \mathrm{~d}$ model group after infection. With the expansion of parasitic lesions, the liver of mice infected with E. multilocularis formed immune tolerance at the middle and late stages (Figures 3, 4A and B).

\section{Dynamic Changes of Fibrosis Related Cytokines and Cell Apoptosis in the Liver of Mice Infected with $E$. multilocularis}

With the continuous infection of $E$. multilocularis, chronic damage leads to a disorder in the liver microenvironment, in which the inflammatory response is gradually aggravated, a large number of hepatocytes are necrotic and apoptotic, and the protective self-repair of fibrosis also widely exists in liver tissue. As a major member of liver fibrosis, HSC is mainly activated by TGF- $\beta$, which mediates inflammatory response and fibrosis changes (active marker, $\alpha$-SMA), and rapidly transforms into myofibroblast-like cell, which further promotes the accumulation of ECM and produces collagen. MMP9 as a double-edged sword in chronic infection, can promote the deposition and degradation of collagen and regulate the development of fibrosis level, liver fibrosis promotes the self-repair of liver tissue at the early stage of infection, and it is reversible. As the infection continues to progress, the degree of fibrosis increases and the liver microenvironment becomes disorganized and irreparable, which may eventually lead to cirrhosis and cancer. In our study, $\alpha$-SMA, as a marker of HSC activation, was highly expressed at both protein and gene levels at the middle and late stages of infection, such as, at $90 \mathrm{~d}$ and $180 \mathrm{~d}$ points $(\mathrm{P}<0.05)$ (Figures $4 \mathrm{C}$, $\mathrm{D}$ and 5). COL1 $\alpha 1$, as a major component of collagen deposition, was expressed similarly to $\alpha$-SMA. MMP9 increased rapidly at $8 \mathrm{~d}$ point (compared with the control group, $\mathrm{P}<0.05$ ), and then decreased rapidly at the middle and late stages of reinfection. Although the expression was higher than that in the control group, it was not statistically significant $(\mathrm{P}>0.05)$. As for liver cell apoptosis, Caspase 3 was highly expressed on $90 \mathrm{~d}$ and $180 \mathrm{~d}$ after infection (compared with the control group, $\mathrm{P}<0.05$ ), and the abnormal expression of these indicators suggested the continuous development and aggravation of liver fibrosis in mice infected with E. multilocularis (Figures 4C, $\mathrm{D}$ and 5).

\section{Discussion}

Human alveolar echinococcosis (AE), caused by the metacestode larval stage of the fox-tapeworm E. multilocularis, is a chronic zoonosis associated with significant modulation of the host immune response. Liver fibrosis, as one of the histopathological phenomena in mice infected with E. multilocularis, is associated with aberrant apoptosis of hepatocytes, collagen formation and liver immune cells inflammation. ${ }^{4}$ Interactions between HSCs, liver resident immune cells, hepatocytes and/or sinusoidal endothelial cells, which constitute the liver microenvironment, are crucial not only for host defense but also for tissue remodeling. ${ }^{9}$ The cross-talk between HSCs and immune cells in the hepatic microenvironment during liver pathophysiology is crucial for ECM deposition and fibrosis development. $^{10,11}$

The disease is characterized by an increased infiltration of immune cells around the lesion, creating an "immunosuppressive" microenvironment that is in favor of persistent parasite infection. At the early stage of infection, parasite stimulation triggers the rapid recruitment of immune cells, such as macrophages and neutrophils. These infiltrated immune cells then produce a large number of cytokines, such as iNOS, small amounts of NO generated by eNOS are thought to be important for liver homeostasis and protective against pathological conditions. In contrast, large amounts of NO generated by iNOS are implicated in the etiologies of many liver diseases, including liver fibrosis. ${ }^{19}$ In the liver, IL-10 can be produced by a variety of cell types including hepatocytes, Kupffer cells, sinusoidal endothelial cells, HSCs, and lymphocytes; its receptor is expressed by progenitor and HSC, the predominant cell types involved in liver fibrogenesis. IL-10 regulates the production of collagen and collagen enzyme, and affects the ECM remodeling by promoting HSC apoptosis and regulating function. ${ }^{20}$ That day number 


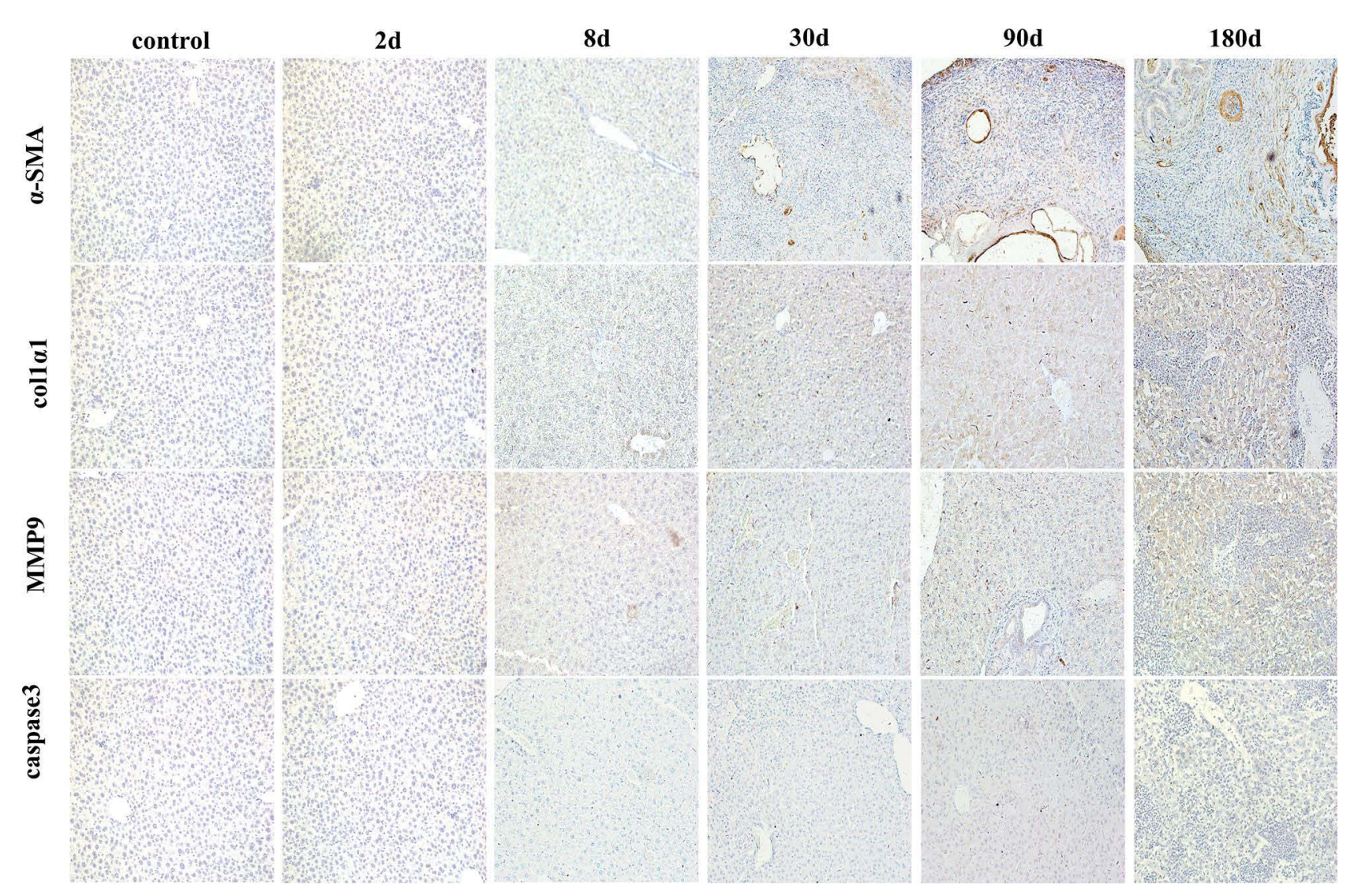

Figure 5 Dynamic changes of fibrosis related cytokines and cell apoptosis in immunohistochemistry $(\times 200)$.

Abbreviations: $\alpha$-SMA, $\alpha$-smooth muscle actin; Coll $\alpha$ I, collagen type I alpha I; MMP9, matrix metalloproteinase 9.

2-60, 60-180 and 180-360 were, respectively, divided as early, middle, and late stages. ${ }^{21}$ In the most susceptible mice, impairment of vital functions due to E. multilocularis progression and metastases is fast and occurs. In addition, susceptible mice mean that the liver tissue is almost completely fibrotic and even calcified without normal cells after more than 180 days of infection. We designated these stages: $2 \mathrm{~d}, 8 \mathrm{~d}$ and $30 \mathrm{~d}$ after infection as early stages; $90 \mathrm{~d}$ and $180 \mathrm{~d}$ after infection as middle and late stages. In our study, the dynamic changes of liver inflammatory cytokines in mice infected with E. multilocularis, showed that iNOS increased rapidly at the early stage (8d), promoting the acute immune response, and maintaining a high level mainly at the middle and late stages of infection. The anti-inflammatory cytokine, IL-10 was mainly elevated mainly at the middle and late stages of infection.

TGF- $\beta$ is a necessary mediator in many fields, such as the immune response, inflammation, matrix synthesis, cell growth, apoptosis, and differentiation. ${ }^{6}$ Human cystic echinococcosis (CE) is another type of echinococcosis, echinococcosis caused by inoculation of the eggs of
E. granulosus. Our previous research has shown that the expression of TGF- $\beta 1$ was upregulated in patients with hepatic $\mathrm{CE}$, which was closely associated with liver fibrosis. $^{22}$ Our results showed that TGF- $\beta$ did not change significantly at the early stage of E. multilocularis infection, but the level of TGF- $\beta$ increased at $30 \mathrm{~d}$ point, and maintained a high expression level at $90 \mathrm{~d}$ and $180 \mathrm{~d}$ points. The expression of $\alpha$-SMA and COL $1 \alpha 1$ at different stages was similar to TGF- $\beta$.

It has also been suggested that fibronectin peptides are generated by limited digestion of MMP9 during liver injury, which acts as local regulatory signals that induce the apoptosis of HSCs and prevent chronic fibrogenesis and fibrosis. ${ }^{23}$ Increased evidence has demonstrated that MMP9 promotes fibrogenesis by activating latent TGF- $\beta$, which stimulates the activation of HSCs. ${ }^{24}$ MMP9 has been demonstrated to induce the apoptosis of activated HSCs. ${ }^{25}$ In our study, the expression of MMP9 in liver tissue of mice infected with E. multilocularis was highly expressed at the early stage (8d), and decreased at the middle and late stages, indicating that early inflammatory cells secreted proteases including MMP9, which decreased 
the deposition of ECM, which might be related to the innate immune response.

Pharmacologic inhibition may attenuate liver injury, inflammation, and fibrosis. ${ }^{26}$ Typically, necroptosis is regarded as a pro-inflammatory mode of cell death that releases intracellular components. However, many studies have shown that necroptosis may have anti-inflammatory effects by blocking the excessive production of chemokines, ${ }^{27,28}$ and our study also supports this conclusion as caspase 3 is highly expressed at $90 \mathrm{~d}$ and $180 \mathrm{~d}$ infection both in protein and gene level. Apoptosis seems to play a positive role in the procession of fibrosis in mice infected with E. multilocularis.

In the experimental model of secondary infection in mice in our study, initially, inflammatory cells are recruited to the liver, which release cytokines mainly to fight against parasitic infections to exert its pro-inflammatory role, later a large number of anti-inflammatory cytokines are released to promote liver repair. Gradually, it develops immune tolerance to E. multilocularis infection; liver fibrosis is constantly progressing; hepatocyte apoptosis or necroptosis; eventually, liver immune microenvironment disorder and fails to repair itself. Many studies on the cytokine profile in $\mathrm{AE}$, in humans and in the experimental models, have stressed that it was never a pure profile, but always a rather mixed profile, ${ }^{17,22}$ such selective and opposite dynamics of inflammatory cytokines at different infected stages release may prevent pathogenic inflammation, and constitute an appropriate response for attraction of effector cells into the periparasitic tissues with the capacity to limit E. multilocularis metacestode proliferation and dissemination. Results of observations in humans and experimental studies in animals suggest that, in the absence of fully effective antiparasitic chemotherapy for AE, modulation of the host's immune response could be envisaged to fight against the parasite and to prevent the disease and/or its complications. The balance of liver microenvironment is regulated tightly by cytokines through an intricate interplay of positive and negative regulatory signals. Our study provides evidence that cytokines have played key roles in the host-parasite interaction in E. multilocularis infection.

In conclusion, the cellular and molecular mechanisms of liver inflammation and fibrosis in mice infected with E. multilocularis are being investigated limitedly. Liver inflammation and fibrogenesis are controlled by complex immunologic pathways that implicate many possible therapeutic targets. Our research may provide some new ideas for E. multilocularis infection.

\section{Data Sharing Statement}

The data used to support the findings of this study are included within the article.

\section{Author Contributions}

All authors made a significant contribution to the work reported, whether that is in the conception, study design, execution, acquisition of data, analysis and interpretation, or in all these areas; took part in drafting, revising or critically reviewing the article; gave final approval of the version to be published; have agreed on the journal to which the article has been submitted; and agree to be accountable for all aspects of the work.

\section{Funding}

This work was supported by the National Natural Science Foundation (82060372, 81760372). Scientific Research Project of Science Department of Xinjiang Autonomous Region (2020E0277) and State Key Laboratory of Pathogenesis, Prevention and Treatment of High Incidence Diseases in Central Asia Fund (SKL-HIDCA-2020YG3, SKL-HIDCA-2021-5).

\section{Disclosure}

Fengming Tian and Tao Jiang are co-first authors of this study. The authors declare that they have no competing interests.

\section{References}

1. Li T, Ito A, Nakaya K, et al. Species identification of human echinococcosis using histopathology and genotyping in northwestern China. Trans $R$ Soc Trop Med Hyg. 2008;102:585-590. doi:10.1016/j. trstmh.2008.02.019

2. Siles-Lucas M, Casulli A, Cirilli R. Progress in the pharmacological treatment of human cystic and alveolar echinococcosis: compounds and therapeutic targets. PLoS Negl Trop Dis. 2018;12:e0006422. doi:10.1371/journal.pntd.0006422

3. Conraths FJ, Probst C, Possenti A, et al. Potential risk factors associated with human alveolar echinococcosis: systematic review and meta-analysis. PLoS Negl Trop Dis. 2017;11:e0005801. doi:10.1371/ journal.pntd.0005801

4. Jeng $\mathrm{KS}$, Lu SJ, Wang $\mathrm{CH}$, et al. Liver fibrosis and inflammation under the control of ERK2. Int J Mol Sci. 2020;21:3796. doi:10.3390/ ijms21113796

5. Higashi T, Friedman SL, Hoshida Y. Hepatic stellate cells as key target in liver fibrosis. Adv Drug Deliv Rev. 2017;121:27-42. doi:10.1016/j. addr.2017.05.007

6. Xu T, Ni MM, Li X, et al. NLRC5 regulates TGF- $\beta 1$-induced proliferation and activation of hepatic stellate cells during hepatic fibrosis. Int $J$ Biochem Cell Biol. 2016;70:92-104. doi:10.1016/j.biocel.2015.11.010

7. Cui W, Jin HB, Li ZW. Mechanism of the transforming growth factor-beta induction of fibronectin expression in hepatic stem-like cells. Braz J Med Biol Res. 2010;43:36-42. doi:10.1590/S0100879X2009007500017 
8. Hsieh CC, Hung $\mathrm{CH}$, Lu L, et al. Hepatic immune tolerance induced by hepatic stellate cells. World J Gastroenterol. 2015;21:11887-11892. doi:10.3748/wjg.v21.i42.11887

9. Medeiros T, Saraiva GN, Moraes LA, et al. Liver fibrosis improvement in chronic hepatitis $\mathrm{C}$ after direct acting-antivirals is accompanied by reduced profibrogenic biomarkers-a role for MMP-9/TIMP-1. Dig Liver Dis. 2020;52:1170-1177. doi:10.1016/j.dld.2020.05.004

10. Khatun M, Ray RB. Mechanisms underlying hepatitis C virus-associated hepatic fibrosis. Cells. 2019;8:1249. doi:10.3390/ cells8101249

11. Byun JS, Yi HS. Hepatic immune microenvironment in alcoholic and nonalcoholic liver disease. BioMed Res Int. 2017;2017:1-12. doi:10.1155/2017/6862439

12. Hernández-Aquino E, Quezada-Ramírez MA, Silva-Olivares A, et al. Naringenin attenuates the progression of liver fibrosis via inactivation of hepatic stellate cells and profibrogenic pathways. Eur J Pharmacol. 2019;865:172730. doi:10.1016/j.ejphar.2019.172730

13. Shiffman M, Freilich B, Vuppalanchi R, et al. Randomised clinical trial: emricasan versus placebo significantly decreases ALT and caspase 3/7 activation in subjects with non-alcoholic fatty liver disease. Aliment Pharmacol Ther. 2019;49:64-73. doi:10.1111/apt.15030

14. Liang B, Guo XL, Jin J, et al. Glycyrrhizic acid inhibits apoptosis and fibrosis in carbon-tetrachloride-induced rat liver injury. World $J$ Gastroenterol. 2015;21:5271-5280. doi:10.3748/wjg.v21.i17.5271

15. Xu R, Zhang Z, Wang FS. Liver fibrosis: mechanisms of immune-mediated liver injury. Cell Mol Immunol. 2012;9:296-301. doi:10.1038/cmi.2011.53

16. Pellicoro A, Ramachandran P, Iredale JP, et al. Liver fibrosis and repair: immune regulation of wound healing in a solid organ. Nat Rev Immunol. 2014;14:181-194. doi:10.1038/nri3623

17. Zhang C, Shao Y, Yang S, et al. T-cell tolerance and exhaustion in the clearance of Echinococcus multilocularis: role of inoculum size in a quantitative hepatic experimental model [published correction appears in Sci Rep. 2019 Feb 27;9(1):3424]. Sci Rep. 2017;7:11153. doi:10.1038/s41598-017-11703-1

18. Choi JS, Jeong IS, Han JH, et al. IL-10-secreting human MSCs generated by TALEN gene editing ameliorate liver fibrosis through enhanced anti-fibrotic activity. Biomater Sci. 2019;7:1078-1087. doi: $10.1039 / \mathrm{c} 8 \mathrm{bm} 01347 \mathrm{k}$
19. Karabulut D, Akin AT, Unsal M, et al. L-Carnitine ameliorates the liver by regulating alpha-SMA, iNOS, HSP90, HIF-1alpha, and RIP1 expressions of CCL4-toxic rats. Iran $J$ Basic Med Sci. 2021;24:184-190. doi:10.22038/IJBMS.2020.47711.10990

20. Choi JS, Jeong IS, Park YJ, et al. HGF and IL-10 expressing ALB:: GFPreporter cells generated from iPSCs show robust anti-fibrotic property in acute fibrotic liver model. Stem Cell Res Ther. 2020;11:332. doi:10.1186/s13287-020-01745-0

21. Zhang C, Wang J, Lü G, et al. Hepatocyte proliferation/growth arrest balance in the liver of mice during E. multilocularis infection: a coordinated 3-stage course. PLoS One. 2012;7(1):e30127. doi:10.1371/journal.pone.0030127

22. Tian F, Liu Y, Gao J, et al. Study on the association between TGF- $\beta 1$ and liver fibrosis in patients with hepatic cystic echinococcosis. Exp Ther Med. 2020;19:1275-1280. doi:10.3892/etm.2019.8355

23. Modol T, Brice N, Ruiz de Galarreta M, et al. Fibronectin peptides as potential regulators of hepatic fibrosis through apoptosis of hepatic stellate cells. J Cell Physiol. 2015;230:546-53. doi:10.1002/jcp.24714

24. Dayer C, Stamenkovic I. Recruitment of matrix metal- loproteinase-9 (MMP-9) to the fibroblast cell surface by lysyl hydroxylase 3 (LH3) triggers transforming growth factor- $\beta$ (TGF- $\beta$ ) activation and fibroblast differentiation. J Biol Chem. 2015;290:13763-78. doi:10.1074/ jbc.M114.622274

25. Atta H, El-Rehany M, Hammam O, et al. Mutant MMP-9 and HGF gene transfer enhance resolution of $\mathrm{CCl}$-induced liver fibrosis in rats: role of $\mathrm{ASH} 1$ and $\mathrm{EZH} 2$ methyltransferases repression. PLoS One. 2014;9:e112384. doi:10.1371/journal.pone.0112384

26. Koyama Y, Brenner DA. Liver inflammation and fibrosis. J Clin Invest. 2017;127:55-64. doi:10.1172/JCI88881

27. Li X, Yao X, Zhu Y, et al. The caspase inhibitor Z-VAD-FMK alleviates endotoxic shock via inducing macrophages necroptosis and promoting MDSCs mediated inhibition of macrophages activation. Front Immunol. 2019;10:1824. doi:10.3389/ fimmu.2019.01824

28. Kearney CJ, Martin SJ. An inflammatory perspective on necroptosis. Mol Cell. 2017;65:965-973. doi:10.1016/j.molcel.2017.02.024
Infection and Drug Resistance

\section{Publish your work in this journal}

Infection and Drug Resistance is an international, peer-reviewed openaccess journal that focuses on the optimal treatment of infection (bacterial, fungal and viral) and the development and institution of preventive strategies to minimize the development and spread of resistance. The journal is specifically concerned with the epidemiology of antibiotic resistance and the mechanisms of resistance development and diffusion in both hospitals and the community. The manuscript management system is completely online and includes a very quick and fair peerreview system, which is all easy to use. Visit http://www.dovepress.com/ testimonials.php to read real quotes from published authors. 